\title{
0 caso Aída Cury: playboys e transviados como representações da juventude em tempos de modernização
}

Marcelo Garson

\section{Resumo}

Estuprada e atirada de um edifício pelos jovens Ronaldo Castro e Cassio Murilo, a jovem Aída Cury amanheceu o dia 14 de julho de 1958 estendida na calçada de Copacabana. De repercussão nacional, esse crime fez com que a delinquência juvenil de classe média se tornasse um tópico central da grande imprensa brasileira de fins dos anos 50. Tomados como sintoma e produto de uma nova ordem social, os chamados "playboys transviados" - existindo por e através de suas representações midiáticas - ajudam a descortinar as ambivalências de um período histórico comumente associado a um otimismo generalizado. 0 objetivo desse artigo, portanto, é perceber como esses personagens dramatizavam as consequências do projeto de modernização nacional baseado na metrópole, espaço em que progresso, cosmopolitismo e diversidade social poderiam significar promiscuidade, vício e corrupção moral.

\section{Palavras-Chave}

Delinquência juvenil. Representação Social. Anos 50.

Marcelo Garson I garson.marcelo@gmail.com Doutor em sociologia pela Universidade de São Paulo - USP, Brasil. Possuiu pós-doutorado em comunicação pela Universidade Federal do Rio de Janeiro - UFRJ, Brasil.

\section{Introdução}

Não faltam dados para comprovar que os anos JK representaram um período de desenvolvimento econômico e estabilidade política notável que permitiram 0 crescimento do parque industrial e a expansão da malha urbana. 0 novo e 0 moderno, portanto, faziam parte não só de um discurso oficial, mas de uma realidade objetiva (BENEVIDES, 1979). Interessa-nos, entretanto, compreender como as expressões materiais dessa modernização foram sentidas e interpretadas no corpo social.

Nesse sentido, os meios de comunicação figuram como espaços privilegiados de análise, pois nem sempre adotam uma posição abertamente contra ou a favor do discurso dominante, que necessariamente os atravessa. As posições contrárias, mais especificamente, não costumam se expressar de maneira aberta e consciente, podendo encontrar canais de expressão subterrâneos que dão voz a anseios e às tensões sociais latentes. 0 debate acerca da delinquência juvenil, que toma de assalto a grande imprensa em fins da década de 50, é um desses momentos. 
É através do rock and roll, dos filmes para juventude e de todo um manancial de bens de consumo norte-americanos que uma certa juventude de classe média faz sua aparição no espaço urbano. Inicialmente pensada como inofensiva, rapidamente se torna um problema social quando associada ao comportamento desviante, até então uma exclusividade das classes subalternas, a julgar pelas páginas policiais. 0 caso Aída Cury é um marco nesse sentido. Estuprada e atirada de um edifício pelos jovens Ronaldo Castro e Cassio Murilo, Aída amanheceu o dia 14 de julho de 1958 estirada na calçada de Copacabana. Ganhando repercussão midiática nacional, o crime se arrastou nos tribunais até 1963, figurando até hoje como uma narrativa paradigmática sobre a delinquência juvenil no Brasil (SANTOS, 2013). 0 que parecia desconcertar a imprensa da época não é somente 0 comportamento debochado dos criminosos frente às autoridades, mas sua origem social abastada. Personagens desse tipo eram tão raros nas manchetes policiais, que foi necessário um novo rótulo para designá-los: playboys transviados.

Não é de se espantar que o debate brasileiro seja concomitante ao enorme impacto na opinião pública das investigações do senado sobre a delinquência juvenil nos Estados Unidos (GILBERT, 1988). A inserção do Brasil em uma sociedade de consumo de dimensões planetárias é consequência de um processo de modernização largamente financiando por capitais estadunidenses; o que fez com que nossos padrões culturais progressivamente mirassem esse país e não mais a Europa (ORTIZ, 1983). A similaridade aparente entre 0 debate norteamericano e brasileiro não leva a concluir que uma problemática estrangeira foi "importada" de forma postiça. É necessário verificar as coordenadas específicas que orientaram a discussão sobre a juventude transviada no Brasil, investigando como e por que prosperou.

0 episódio se tornou modelar para analisar as complexidades da década de 50 , ao mostrar que 0 crescimento urbano tanto poderia ser celebrado como sintoma de inserção do Brasil no capitalismo globalizado do pós-guerra, quanto parecia encapsular uma série de incertezas em relação às suas consequências a longo prazo. 0 debate acerca dos playboys transviados foi uma maneira de colocar em xeque o projeto de modernização baseado na metrópole - considerada vitrine da prosperidade e cosmopolitismo, mas também de promiscuidade, miscigenação social e vício - e nas classes médias - cujo estilo de vida, orientado pelo consumo, representava a um só tempo prosperidade econômica, além de individualismo e hedonismo.

Isso ficava ainda mais evidente através dos filhos da elite, justamente aqueles responsáveis por perpetuar essa ordem. Ao expressar, ao mesmo tempo, os efeitos perturbadores do presente e as promessas de progresso no futuro, a juventude, construída historicamente como local de transição, choque e passagem, torna-se um local privilegiado para especular 
sobre as consequências de um rearranjo de forças, podendo ser lida, assim, enquanto metáfora da mudança social (PASSERINI, 1996; HALL, JEFFERSON, 1978). Contrastando as representações da delinquência juvenil que emergem do caso Aída Cury com aquelas que 0 antecedem, o objetivo deste trabalho é analisar de que maneira a construção midiática da juventude ajuda a compreender as ambivalências da nova paisagem urbana e cosmopolita na qual se baseava o projeto moderno brasileiro de fins da década de 50. Isso evidencia um retrato mais complexo dessa época histórica, comumente associada a um otimismo generalizado.

Iniciamos 0 texto com a reconstituição do conceito de representação, central para definir os marcos teóricos e metodológicos que vão guiar nossa investigação. Em seguida, analisamos como a emergência de uma certa imagem da juventude, tanto no Brasil quanto nos Estados Unidos, revela sobre as dinâmicas conjunturais e estruturais de cada país. Por fim, analisamos a construção dos playboys e transviados, categorias nativas do discurso midiático, e de que maneira elas se cruzam no caso Aída Cury, fazendo da juventude um fórum para se especular sobre os efeitos ambivalentes da modernização na paisagem urbana de fins da década de 50.

\section{Mídia e representação social}

A noção de representação social possui um amplo percurso no campo das ciências sociais, remetendo a autores tanto da sociologia clássica (DURKHEIM, 1989), quanto contemporânea (BOURDIEU 1996, BECKER, 2009) e também da psicologia social (MOSCOVICI, 1978). No que tange à análise dos meios de comunicação, 0 conceito foi, e ainda é, amplamente utilizado pelos Estudos Culturais. Especialmente conectado à questão da identidade cultural, trata-se de uma maneira de investigar de que maneira o enquadramento midiático participa decisivamente da maneira como grupos sociais, instituições e indivíduos são posicionados socialmente. Discutir a representação é lidar com relações de poder e discurso.

Surgido na década de 60, os Estudos Culturais deram um novo folego às análises midiáticas, então dominadas pelo paradigma funcionalista norte-americano que se preocupava, fundamentalmente, com os efeitos sociais dos meios. Amparada nas ciências comportamentais, essa perspectiva fazia uso de testes empíricos com 0 intuito de medir a influência das mídias nas escolhas do público. Não surpreende, portanto, que as eleições tenham se tornado 0 seu caso teste. The People's Choice: How the Voter Makes Up His Mind in a Presidential Campaign tornou-se um dos textos chaves de Paul Lazarsfeld, o maior ícone dessa corrente. Ao analisar como os eleitores definiam seu voto no decorrer de uma campanha, a obra postulava que a propaganda irradiada pela mídia não atingia a audiência diretamente, sendo antes mediada pelos líderes de opinião, sujeitos com 
maior exposição aos meios e que redistribuíam as informações e influenciavam seu círculo social. Dessa obra também decorria a ideia de que os veículos agiam mais no reforço de opiniões préexistentes, do que em sua modificação. Essas duas premissas - a ação dos meios não atingia a audiência diretamente e seus conteúdos não tinham o poder persuasivo que lhes era então creditado - tornaram-se a base dos chamados efeitos limitados, perspectiva que desacreditava o poderio das comunicações no controle das consciências, postulado vigente até os anos 40 . Para os funcionalistas, portanto, o pluralismo e a democracia do pós-guerra pareciam salvos de uma suposta tirania midiática.

Em direção francamente oposta, o Centro de Estudos Culturais Contemporâneos (CCCS) da Universidade de Birmingham, a partir dos anos 60 , teve como meta estudar a relação permanente e duradoura entre a mídia e a ordem social instituída. Nessa perspectiva, os meios são considerados instâncias fundamentais de produção e circulação de sentido nas sociedades modernas. Ao redor deles, organizam-se valores, práticas e comportamentos que contribuem decisivamente na sedimentação, ou modificação, da ordem social instituída. Questionar a mídia em sua relação com o poder, a estrutura social e a conjuntura política tornava-se uma questão central. É justamente a noção de pluralismo, na qual se assentava a perspectiva funcionalista, que cabia agora problematizar (HALL, 2010).
Influenciados pelo marxismo que então grassava nos meios intelectuais da esquerda britânica, autores como Stuart Hall e Raymond Williams buscaram dar autonomia relativa ao campo da cultura, pensado não mais como um reflexo de uma superestrutura econômica, mas elemento ativo na construção e sedimentação da ordem dominante, amparada na criação de mecanismos de aceitação das relações assimétricas de poder enquanto dados naturais. Tratava-se, portanto, de estudar os mecanismos de formação de um consenso.

Para tanto, duas noções se fizeram presentes: ideologia e hegemonia. Partia-se, portanto, da ideia cara a Althusser de que "a ideologia representa a relação imaginária dos indivíduos com suas condições reais de existências" (ALTHUSSER, 1980, p.77), unindo-a ao conceito de Gramsci que tematizava o poder de moldar 0 consenso e legitimar o poder instituído.

Esses dois conceitos ajudavam a perceber que a manutenção de uma ordem social não dependia somente de aparatos repressores amparados na violência física, mas fundamentalmente de um trabalho de produção do consentimento que se dava ao nível simbólico. Tomando a mídia como meio privilegiado de produção de sentido e cristalização de esquemas interpretativos da realidade, tornava-se de suma importância entender como ela operava em relação à ordem dominante. Defendendo que as mídias não funcionam somente como canais de transmissão 
de mensagens, que então poderiam, ou não, ser "distorcidas", Hall sublinha o papel ativo dos veículos na construção da própria realidade que buscam representar. Se a representação é tomada enquanto "produção de significado através da linguagem" (HALL, 1997, p.16), os meios, como produtores de sentido, agem como espaços em que a ordem simbólica dominante é produzida, reproduzida, mas também questionada.

Assim, as representações sociais não refletem, mas constroem através de práticas linguísticas certos domínios do real. Não se quer com isso dizer que o mundo não exista fora da linguagem, mas sim que é a partir dela que ele ganha sentido. É através das representações que formamos nossas concepções de classe, raça, etnia e geração, é por meio delas que julgamos, enquadramos e modificamos a realidade ao nosso redor. Elas, portanto, têm uma função ideológica clara na medida que circulam "imagens, conceitos e premissas que oferecem quadros de referência através dos quais representamos, interpretamos, compreendemos e depreendemos sentidos de alguns aspectos da existência social" (HALL, 1981, p.31).

Isso faz com que a dimensão simbólica tenha efeitos reais em nossa vida cotidiana. A análise das representações na mídia tem como meta enxergar de que maneira a produção de sentido se liga às estruturas de poder mais amplas, participando da sua reprodução ou desmonte. Todo o tipo de narrativa midiática - imagens, textos e sons - para se fazer inteligível precisa se amparar em noções já partilhadas com a audiência que aparecem no discurso como dados naturais. Interessa, portanto, compreender as estratégias discursivas de naturalização ou desnaturalização desses esquemas interpretativos. Se as narrativas midiáticas não são 0 espelho de uma ordem social instituída, cabe analisá-las com o intuito de perceber o trabalho de significação levado a cabo. Alguns tópicos sobre as representações tornam-se, portanto, essenciais. Que disputas sociais elas dramatizam? Como elas se ligam à estrutura desigual de poder? Que grupos estão sendo representados? De que forma? Como essas representações mudam com o tempo e em privilégio de quem?

Cada sociedade tem seus esquemas classificatórios que agem inconscientemente e à revelia dos sujeitos que os utilizam. Esses esquemas têm relação íntima com a estrutura social na medida em que participam mesmo da sua construção e reprodução. As representações são um caso privilegiado de perceber esses esquemas em ação e de que maneira eles agem seletivamente privilegiando certos enquadramentos do real em detrimento de outros. Nas palavras de Pierre Bourdieu, as representações agem na produção de visões e divisões, ou seja, funcionando como esquemas interpretativos do real, agem em sua própria repartição social desigual (BOURDIEU, 1996, p.111).

Para os Estudos Culturais, a análise dos meios de comunicação, portanto, era uma forma de 
historicizar as estruturas de sentido em conexão com as estruturas sociais. Isso fica bastante claro em Resistance through Rituals, um dos primeiros projetos conjuntos de folego do CCCS. Organizado por Stuart Hall e Tony Jefferson (1978), contou com a participação de diversos pesquisadores que tinham por objetivo explicar o surgimento, no pós-guerra inglês, de uma série de subculturas juvenis da classe trabalhadora como skinheads, mods e rockers. Afastando-se das definições que circulavam na mídia que, então, qualificavam esses grupos juvenis como resultado da alienação promovida no mercado ou sintoma de comportamento delinquente, os pesquisadores do CCCS entenderam que a identidade de cada grupo era 0 produto de uma relação entre a cultura dominante e a cultura da classe trabalhadora, traduzida em um consumo cultural bastante específico, simbolizado pela indumentária, gírias, gosto musical e rituais de sociabilidade. A crítica ao discurso midiático, portanto, passava por uma pormenorizada reconstituição histórica que situava a classe trabalhadora na estrutura da sociedade inglesa do pós-guerra. Ao mesmo tempo, buscava-se compreender de que maneira os discursos dominantes sobre as subculturas enxergava uma relação natural entre a juventude e o comportamento desviante. Criticar as narrativas hegemônicas era uma forma de reescrever a história e 0 sentido desses grupos sociais subalternos. Se é através das representações que os entendimentos coletivos são criados e que 0 consenso é forjado, é mediante sua crítica que eles podem ser desarticulados.
A noção de representação, portanto, é de fundamental importância para este trabalho. Nosso objetivo é perceber de que maneira categorias nativas do discurso jornalístico, como o playboy e transviado, que até então não se comunicavam, são ressignificadas em fins da década de 50. 0 caso Aída Cury é um momento crítico nesse processo, pois obriga a refletir sobre a construção de um jovem delinquente de classe média. Esse personagem, até então inédito das páginas policiais, demandava um novo esforço de classificação que, por sua vez, está impregnado dos temores e ansiedades decorrentes das profundas modificações sociais experimentadas pela sociedade brasileira do período. Se os meios de comunicação não refletem as estruturas sociais de forma mecânica, é interessante perceber como o plano do discurso nos ajuda a compreender os diferentes sentidos atrelados a uma ordem social emergente.

Ao analisar jornais e revistas cariocas de grande circulação entre os anos de 1956 e 1963, da eclosão do crime, até 0 seu julgamento final, buscaremos analisar os significados contrastantes ligados aos playboys transviados. Nosso objetivo é compreender de que maneira a juventude se vê representada, através de quais categorias e valores, que fazem dela um ponto de convergência sobre problemáticas mais amplas. Busca-se, portanto, perceber como os personagens são alocados na narrativa do caso Aída Cury e de que maneira a organização dos "fatos" elenca causas, consequências e soluções que dizem respeito não 
só ao crime em questão, mas à própria ordem social como um todo. Dessa maneira, entende-se a estrutura social em intima associação com 0 discurso midiático que contribui para a modificação dessa estrutura no momento mesmo que a narra.

\section{Representações juvenis no Brasil e nos Estados Unidos}

A maneira como a imprensa carioca pensa a juventude na segunda metade da década de 50 é diretamente influenciada por dois personagens que já povoam a mídia norte-americana: o playboy e o teenager, cujas identidades se ancoravam na maneira como investiam o tempo livre na esfera do lazer. A abundância e o prazer ocupavam o lugar da disciplina e austeridade, valores que haviam marcado a discurso da depressão e o período de guerra. 0 hedonismo torna-se um dos signos estruturantes da ideologia de uma sociedade de consumo em rápida expansão, bem como de uma classe média que lhe dava suporte encontrando no playboy e no teenager seus modelos ideais.

Nesse sentido, eles funcionavam como modelos de aspiração (OSGERBY, 2001).

A figura do teenager era um fruto da relação dinâmica entre a high school e a cultura de massas: enquanto a escola cristalizava uma unidade geracional - já que aumentava o tempo de contato do jovem com os seus pares -, filmes, músicas, roupas, programas de TV e rádio tornavam-se os signos mais visíveis de uma nova cultura juvenil que se distinguia por gírias, regras de status, modos de gastar o dinheiro e 0 aproveitar 0 tempo livre; práticas atreladas a um relacionamento específico com amigos, pares amorosos, escola e família.

Já o playboy representava um novo estilo de vida adulto e masculino voltado para a celebração do prazer, do lazer e do consumo. Se nos Estados Unidos era representado pelas classes médias, aqui encontrava refúgio nas classes abastadas. É através das colunas sociais que empresários, políticos e celebridades midiáticas ostentavam sua rotina marcadas por festas e eventos diversos. De substantivo, a nomenclatura também podia ganhar função adjetiva quando utilizada pejorativamente para traduzir uma posição individualista e displicente frente à vida e ao futuro.

É necessário compreender alguns detalhes do desenvolvimento de cada uma dessas categorias discursivas para, então, perceber como desembocaram na noção de playboys transviados que plasmou o debate sobre a delinquência juvenil no Brasil.

0 teenager reconfigurou as representações da juventude nos Estados Unidos e na Europa, que desde 0 início daquele século, em larga medida, orientavam-se pela noção de adolescência. Concebida no âmbito, principalmente, da psicologia, o conceito diagnosticava uma fase da vida por modificações biológicas que resultariam em um comportamento turbulento e potencialmente ameaçador (FREIRE FILHO, 2006; 
SERCOMBE, 1996; PALLADINO, 1997). A partir de então, naturalizava-se a relação entre a juventude e 0 comportamento desviante, 0 que legitimava a subvenção adulta como imperativo disciplinar e dificultava falar em autonomia e identidade propriamente adolescentes.

É justamente essa autonomia relativa que encontra suporte no caso do teenager, amparada, principalmente no desenvolvimento singular dos meios de comunicação de massa no pósguerra. Essa indústria cultural não só inaugurou um segmento de mercado jovem, ao redor do qual gravitavam uma série de práticas e rituais específicos, mas uma maneira mesmo de enxergar, enquadrar e interpretar esse personagem tão particular. É isso que nos permite falar da emergência de uma cultura propriamente juvenil na qual o componente midiático é intrínseco. Assim, estudar a moderna identidade jovem é também estudar a maneira como ela é articulada pelos meios de comunicação, tanto através de bens culturais, quanto de representações sociais e culturais (GROSSBERG, 1994).

Ela ajuda a compreender os embates que envolvem a esfera midiática na produção da ideia de juventude no pós-guerra. É no choque entre os universos da high-school e da cultura de massas que 0 debate norte-americano se orienta. Enquanto as mídias ganhavam terreno, eram cada vez mais criticadas por incentivarem um estilo de vida hedonista que parecia ser a antítese dos valores propalados pela escola, igreja e família, instâncias tradicionais de socialização juvenil e reprodução da ordem social. Tratavase de um embate no sentido de determinar que tinha o poder e a responsabilidade por moldar os valores culturais norte-americanos. A polêmica gerou calorosas discussões em comitês do senado estadunidense, além de produzir uma cruzada moral que se voltou principalmente contra a indústria de quadrinhos, impactando também 0 rock and roll e os filmes juvenis. 0 segmento de mercado jovem, portanto, tornava-se uma das explicações para as questionáveis estatísticas que apontavam a aumento da delinquência juvenil (GILBERT, 1988).

Isso, no entanto, não deteve a exportação global desses produtos para o resto do mundo. No Brasil, o crescimento industrial e a expansão urbana tornavam-se a expressão material do discurso da modernização e da prosperidade brasileiras, que caminhavam de mão dadas com a ideologia da afluência norte-americana do pós-guerra. $\mathrm{Na}$ segunda metade dos anos 50, assistíamos à chegada da vitrola $h i-f i$, das batatas chips, do shampoo e dos shopping centers, atreladas às noções de praticidade, conforto e progresso (MELO; NOVAIS, 1998). Embutidas em filmes como Juventude Transviada, O Selvagem e Sementes da Violência, bem como nos discos de rock and roll, a noção de teenager aos poucos ganhava terreno. Ao mesmo tempo, a imprensa brasileira tentava compreender essa categoria de sujeitos que, mesmo morando com os pais, pareciam comportar-se segundo suas próprias regras. 
A juventude americana goza de uma liberdade que espanta e escandaliza 0 estrangeiro. Em um país onde a moral é referenciada ao mais alto grau, é surpreendente constatar que a relação entre rapazes e moças não obedecem, de forma alguma, aos preceitos tradicionais. Novas convenções foram criadas permitindo tranquilamente ao jovem fazer sua iniciação amorosa'.

Esse fragmento fazia parte da série $A$ juventude de 1958 e o amor na qual o Correio da Manhã detalhava como certas práticas amorosas difundidas a partir da high-school iam contra os valores da própria instituição. Isso evidenciava um lapso geracional entre os teenagers e seus pais, também fomentado por um consumo cultural exclusivamente juvenil que parecia estar construindo um universo inacessível aos adultos. É justamente essa descontinuidade que levaria ao debate da delinquência juvenil, um rótulo difuso para enquadrar comportamentos que fugiam às normas tradicionais (GILBERT, 1988).

Influenciados pelas noções de consumo, hedonismo e delinquência, os meios de comunicação brasileiros se esforçavam por qualificar os grupos de jovens que então emergiam no espaço urbano. É mediante a reciclagem do material simbólico estrangeiro que construiremos nossos próprios paradigmas juvenis, evidenciando uma confluência entre o local e o global. Ao invés de detonar uma cruzada moral contra os meios de comunicação de massa, tal como nos Estados
Unidos, 0 debate sobre 0 comportamento juvenil no Brasil, em fins dos anos 50, expressou uma reação ambivalente à vida cada vez mais caótica e heterogênea dos grandes centros urbanos. A juventude, portanto, torna-se um terreno onde era possível inquirir sobre as expectativas e temores acerca das mudanças advindas do ingresso do Brasil em uma nova ordem social.

\section{Os transviados de ontem e hoje}

No início de 57, chegava aos cinemas cariocas Ao Balanço das horas (Rock around the Clock). Responsável por popularizar o rock and roll nos Estados Unidos e resto do mundo, o filme continha intérpretes de sucesso, como Bill Haley e seus cometas, que embalavam as acrobáticas coreografias de duplas de jovens dançarinos. A estreia do filme, no Brasil, vinha cercada de uma publicidade que ressaltava seus efeitos delirantes. 0 público juvenil seria o mais afetado, vandalizando cinemas, desacatando a polícia, destruindo carros e envolvendo-se em brigas. Seu destino natural parecia ser a prisão ou o hospital.

De fato, a imprensa carioca e paulista registrou uma série de distúrbios causados por essa audiência na estreia do filme. Parecia-se confirmar as expectativas de que o rock era "um enfeitiçamento mórbido, muito semelhante ao do culto 'vaudou'(sic) do Haiti”' , caracterizado por "contorções estranhas, que já foram apelidadas 
de 'macumba branca3". Entretanto, grande parte dos especialistas consultados pelos jornais, principalmente psicólogos, caracterizavam o novo gênero como "um fenômeno perfeitamente normal da mocidade, sem nenhum caráter específico." ${ }^{\prime 4}$ Um rótulo bastante utilizado para caracterizar essa juventude de classe média à época foi 0 de "geração coca-cola". Assim, os tumultos no cinema adquiriam um ar quase infantil de travessura. Criticava-se a atenção exagerada da polícia sobre aquele grupo, já que se tratava-se da "rapaziada 'bem' da zona sul, nossa melhor sociedade (... $)^{5}$ ". Nos textos mais críticos se empregou o rótulo "juventude transviada", sugerindo uma associação entre 0 rock e 0 comportamento desviante, 0 que, de partida, não teve grande impacto.

Juventude Transviada, o filme, estreou no Brasil em setembro de 56, portanto antes de $A o$ Balanço das Horas, mas sem grande alarde. A fita que tornou James Dean um modelo de jovem rebelde, avesso à escola e à família, tornouse, por aqui, um objeto de especulações mais estéticas, do que sociais.

'Juventude Transviada' forma com '0 Selvagem' (..) e 'Sementes da Violência' (..) uma importância trilogia sobre a delinquência juvenil, (..) lançando sobre os pais (..) a responsabilidade do desvio dos filhos para o cami- nho do vício ou do crime. Não é a tese, porém, que importa (..), [mas] 0 impacto dramático de um filme que dá ao problema uma interpretação menos sociológica do que poética ${ }^{6}$

No ano seguinte, entretanto, o jornal Última Hora ocuparia suas páginas durante várias semanas com uma extensa reportagem dividida em episódios. Tal como uma ficção policial em capítulos, a série, que documentava

"o drama de uma juventude dominada pelo desre-
gramento sexual e descontrolada pela total ausên-
cia de responsabilidade paterna", iniciava com
um apelo: "urge enfrentar a dura realidade (...) an-
tes que o fenômeno da delinquência juvenil - que
já constitui uma chaga social nos Estados Unidos
- contamine também a mocidade brasileira ${ }^{8 "}$.

A matéria expunha o submundo de um grupo de jovens de classe média, regado a festas, álcool e maconha. 0s "selvagens da lambreta [que] imitam Marlon Brando e James Dean"9 varavam as madrugas apostando corrida em automóveis muitas vezes roubados. A prática, conhecida como lenha, só era menos reprovada que a "curra", rótulo que designava 0 estupro de jovens virgens, após um meticuloso plano de execução.

Essa série de reportagens prepararou terreno para 0 Caso Aída Curi que, a partir de julho de 58,

Uma notícia sôbre o "rock and roll”, a estranha loucura que perturba a juventude moderna Correio da Manhã, 13/11/56, p.3.

A Macumba branca, Jornal do Brasil, $1^{\circ}$ caderno, 18/11/56, p.5.

Declaração do psicanalista Edgard Guimarães ao Correio da Manhã, 24/2/57, 5 Caderno, p.1 50 "rock'n roll" toma Copacabana de assalto, $A$ Noite, $1^{\circ}$ caderno, $A$ Noite, $1^{\circ}$ caderno, 12/1/57, p.5. 6 Correio da Manhã, 30/8/56, $5^{\circ}$ Caderno, p.5.

5 Alerta aos pais irresponsáveis: seu filho já chegou às fronteiras do crime, Última Hora, 6/3/57, p.6. ${ }^{8} \mathrm{Idem} .{ }^{9} \mathrm{Idem}$. 
tornaria a juventude transviada uma categoria corrente na imprensa. Uma das versões mais difundidas do caso, dava conta de que a jovem Aída Curi teria sido aliciada até um apartamento em Copacabana e, em seguida, currada por Cassio Murilo, de 17 anos, e Ronaldo Castro, de 18, dois jovens de classe média alta que posteriormente teriam atirado o corpo do alto de um prédio ${ }^{6}$, simulando suicídio. Outra versão defendia que a jovem havia se lançado à morte justamente para escapar aos agressores e conservar sua "pureza". Aída Curi, filha de imigrantes sírios, órfã de pai, recém egressa de um internato de freiras, jovem trabalhadora e sistemática, "moça de passado ilibado, ingênua mesmo"11 seria uma vítima não só dos "monstros" Cassio e Ronaldo, mas também do zelador do prédio, que parecia ter facilitado, quando não participado, do crime. A cobertura que se fez do caso buscava expor que o comportamento desviante não era uma exclusividade das classes populares, mas um produto da atmosfera de vício típica das grandes cidades. Nessa perspectiva, o hedonismo e inconsequência da juventude de classe média, portanto, seria um efeito da erosão da autoridade e dos valores tradicionais, um produto das rápidas mutações experimentadas no meio urbano. Assim, mais do que Cassio, Ronaldo e Aída, o grande protagonista do caso era a própria metrópole brasileira e seus efeitos sobre a psicologia das massas.

A delinquência juvenil já era tema corrente na imprensa carioca, entretanto, até a década de 50, é majoritariamente com as classes baixas que aparecia associada. "A fina flor da gatunagem, pivetes com várias entradas na polícia, arrombadores, (...) a escória da sociedade (...) vivendo como animais, trazem na alma o germe da revolta ${ }^{7 "}$ é como são descritos os infratores encarcerados no Serviço de Atendimento ao Menor, "uma infecta pocilga, (...) com centenas de menores na mais dolorosa promiscuidade" ${ }^{8 "}$. Reforçando o tom de exclusão, os retratos dos detentos apareciam justapostos, sem identificação e repletos de tarjas pretas. A composição enfatizava o conjunto em detrimento do indivíduo, dando a impressão de um bando homogêneo, uma turba ameaçadora de seres sem nome e sem rosto, entregues a seus instintos primais ${ }^{9}$. 
Figura 1: Típicas representações da juventude transviada
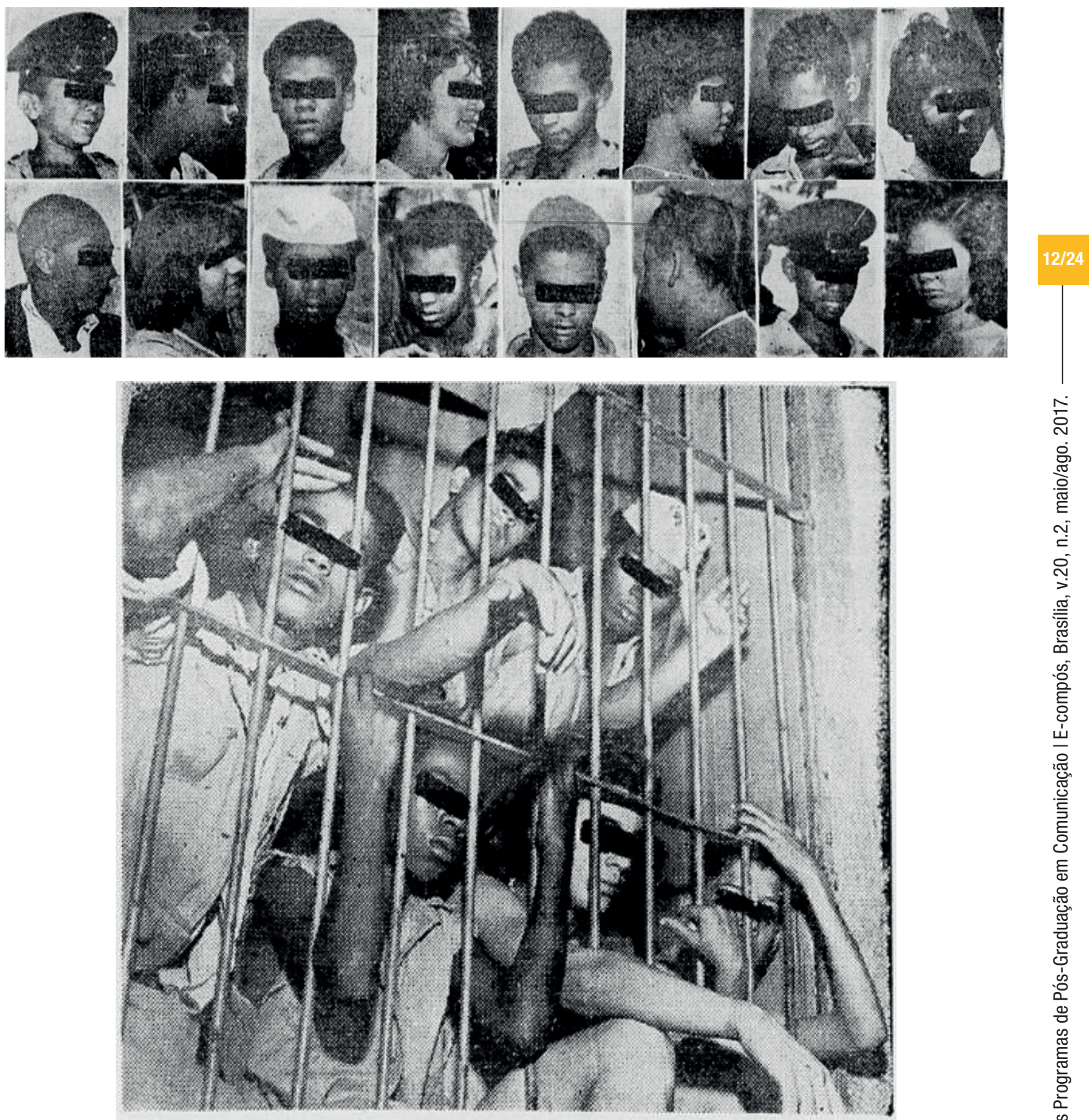

Isto é o SiMH, sem retoque. Na verdade näo é um xadrez. Sŭo menores rotos, unma dependência do infecto alojamento de उä́o Cristóvão, onde meninos de boa formaçäo moral fican ombro "ambro com "fina flor da gatumagem. E todos sob a protegäo do Estado... que protegão, meus senhores... 
As novas representações de transviados que se popularizaram após o caso Aída Cury, do contrário, miravam os filhos da elite. Agora a explicação da delinquência estava fundamentalmente ancorada na permissividade das famílias, responsáveis pela falta de limites e displicência dos jovens. 0 ambiente corrompido dos grandes centros funcionava como um ingrediente fundamental, tornando esse caso modelar para discutir os temores e ansiedades acerca da nossa modernização.

A grande repercussão do crime, em boa medida, explica-se pelo seu local de ocorrência, o bairro de Copacabana. Desde meados do século, o seu crescimento demográfico parecia desarranjar, de baixo para cima, o microcosmo de uma elite social. A intensa especulação imobiliária, que se iniciara nos anos 40, levou à proliferação de minúsculos apartamentos alocados em enormes edifícios que contrastavam com as espaçosas unidades da orla ocupadas pelas elites tradicionais. Em paralelo, há uma expansão do setor de comércio e serviços que resulta no grande afluxo de trabalhadores vindos, muitas vezes, dos subúrbios cariocas - serventes, empregadas domésticas, faxineiros -, que se misturam aos residentes.

Copacabana se transformou de pacato bairro à beira-mar, com casas em espaçosos terrenos, nesta famosa 'floresta de cimento armado'. De lugar relativamente isolado, passou a ser uma espécie de outro 'centro' da cidade, onde todas as pessoas vão para fazer compras, 'divertir-se' e, cada vez mais, trabalhar (VELHO, 1972, p.27).

0 grande número de bares, restaurantes, cinemas, teatros, clubes e principalmente boates, compunha o centro dinâmico da boêmia carioca, antes situado na Lapa (LENHARO, 1995). Ao mesmo tempo uma vitrine do consumo cultural moderno - na música, uma de suas maiores expressões é a bossa nova -, o bairro também parecia oferecer toda a sorte de diversões promíscuas a uma multidão anônima. É daí que se originam os delinquentes de classe média, "exemplos da fina flor da high society, educados pelos trejeitos e frustrações do falecido James Dean", ou ainda "'filhinhos e sobrinhos de papai' que fazem parte da famigerada juventude transviada de Copacabana que dança 'rock and roll', veste camisa vermelha, masca chiclete e usa 'blue jean' (sic)"10.

As ruas do Rio de Janeiro vão ganhando feições novas de acordo com certas coisas que acontecem. A rua Senador Dantas, por exemplo, era uma pacata rua de grandes sobradões ainda bem ontem. Existiram nela algumas pensões de boa comida onde os estudantes pagaram pouco e já comeram sem perigo. Isso não foi naquele 'Rio Antigo' que Luís Edmundo descreve e sim, já um Rio, parecido com esse de hoje, mais sereno e melhor que esse que aí está. De repente surgiu naquela rua a primeira loja de discos; em seguida uma bonita vitrine de artigos para homens, e (..) novas casas de música, novas lojas foram entrando em fila e tornando a velha e até tristonha Senador Dantas uma festa de cores e 
muita música (..). Uma rua sem perigo. Falei de perigo e lembrei-me de outras ruas, principalmente as de Copacabana. Aquela Prado Junior fez nascer cabarés perigosos e sem policiamento. Crimes, vícios, gritos dentro da noite é o presente que podem ganhar os habitantes pacatos (..). Uma filial daquela rua é a Rodolfo Dantas (..), ela está germinando um mundo de cafés em pé, botequins também em pé, cujas luzes estão chamando uma nova casta de vagabundos. Antigamente esta denominação era dada aos escurinhos do morro, chamados malandros a quem a polícia perseguia sem piedade. Hoje não! 0 que está acontecendo na rua, dentro das madrugadas é a algazarra perigosa de rapazes de boa cor, com documentos de boas famílias e comportamento de malandros. Talvez seja a influência de 'Sementes da Violência', a notícia da de (sic) Elvis Presley ou a morte de James Dean. Tudo isso tem acontecido nos Estados Unidos por conta de uma infinidade de fatores psicológicos, e aqui, mais e tristemente, por força de imitação ridícula. Estamos também - embora pareça incrível - adotando o 'Rock and Roll'. De acordo com o famoso psicólogo Jean Rousselet, tudo isso decorre da 'falta de iniciação que nas sociedades antigas marcava em cerimônias e provas de afirmação psicológica, a puberdade'. E é uma pena que os nossos jovens deem em plena rua a prova de ausência de uma das mais belas coisas que um homem pode ganhar em hora certa e em idade exata ${ }^{11}$.
Anteriores ao caso Aída Cury, comentários claramente racistas e classistas como esse sublinhavam os indesejáveis impactos das rápidas modificações experimentadas no bairro. A ocorrência do crime, protagonizado por personagens típicos da paisagem urbana - um porteiro, dois jovens de classe média e uma filha de imigrante sírio - só veio a dar força àqueles que enxergavam a falência de um projeto modernizador baseada no desenvolvimento urbano e miscigenação social. Nessa perspectiva conservadora, a depravação moral das classes baixas parecia se aliar ao hedonismo e à falta de limites das classes altas produzindo os transviados, um produto para o qual contribuía a própria geografia de Copacabana, repartida entre 0 morro e 0 asfalto. A vítima, Aída Curi, era uma órfã, religiosa, trabalhadora, que buscava a todo o custo "vencer na vida". Ela representava, portanto, a figura prototípica da imigrante que, buscando um lugar ao sol na cidade grande, acabaria sendo engolida por sua atmosfera de caos e depravação moral. 
Figura 2: A geografia da delinquência em Copacabana

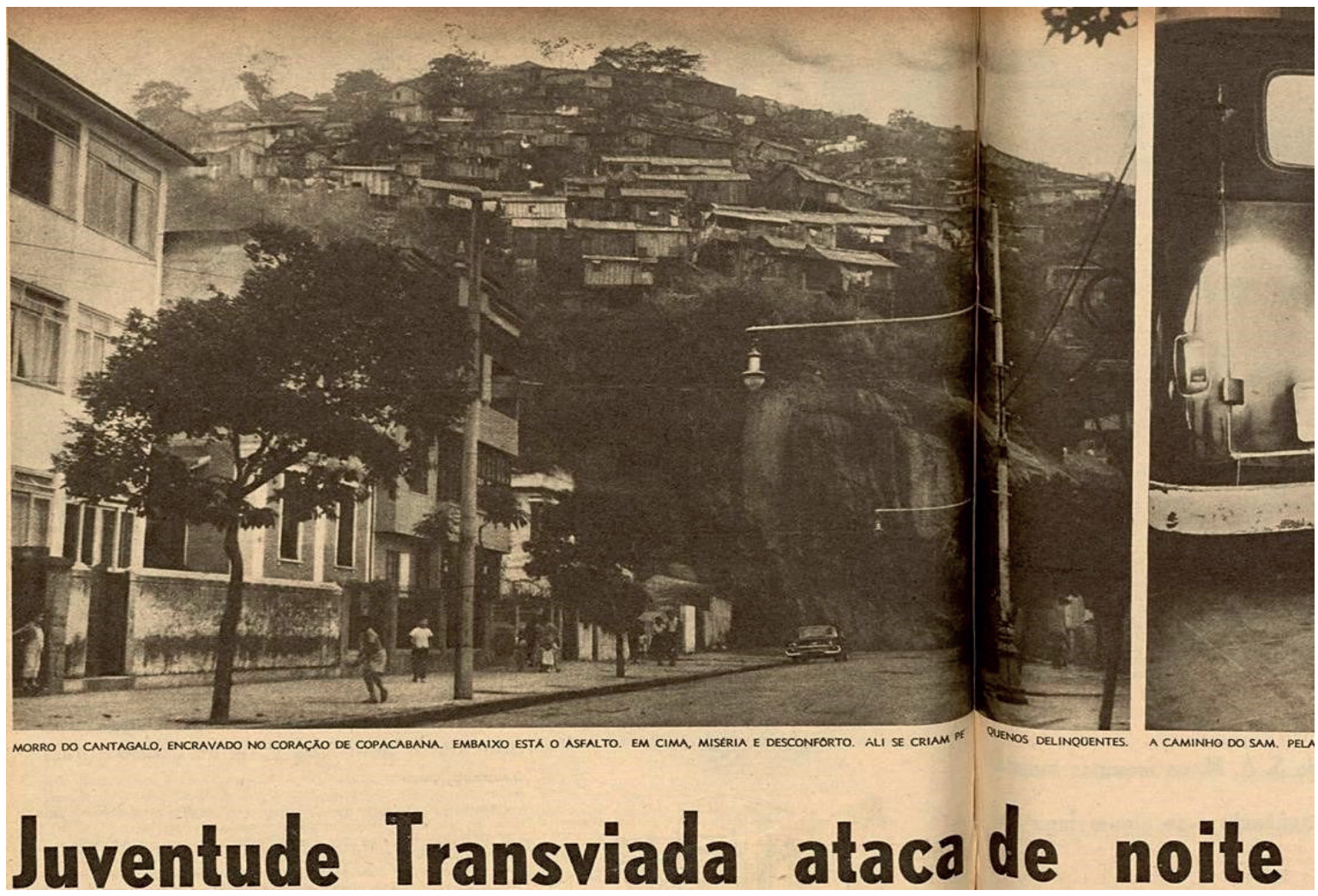

Fonte: 0 Cruzeiro, 26/7/58, p.40.12

A discussão acerca dos transviados, portanto,

Dos playboys aos playboys transviados

cristalizava no jovem uma série de anseios a

respeito da nova paisagem social que encontrava

0 caso Aída Curi não dá somente um outro seu microcosmo em Copacabana. Como

sentido à categoria de transviado, mas também

resultado, um imaginário bastante difuso emergia

à de playboy. Cassio Murilo e Ronaldo Castro se

em fins da década, misturando preconceito

tornam o paradigma dos playboys transviados, uma

racial e de classe aos símbolos de consumo que

nos vinham através da cultura de massa norte-

nova categoria que passa a povoar as reportagens

policiais. Para se compreender, no entanto, 0

americana. Ainda assim, não tivemos, por aqui,

nada parecido com a cruzada moralizante contra

filmes, revistas e músicas que tomou os Estados

Unidos de assalto na mesma época.

porquê dessa fusão de conceitos e como ela exprime

as ambivalências do processo de modernização

brasileiro, é necessário compreender a gênese e a

apropriação da noção de playboy na mídia brasileira.

120 Cruzeiro, 26/7/58, p.40. Na legenda da foto lemos: "Morro do Cantagalo, encravado no coração de Copacabana, embaixo está o asfalto, em cima miséria e desconforto. Ali se criam pequenos delinqüentes (sic)". 
Assim como o teenager, o playboy é 0

representante de um estilo de vida particular ligado a uma nova ética de classe média norteamericana, ancorada na promoção do prazer e distinção por meio do consumo. Popularizado pela famosa revista homônima, tratava-se de um construto ideológico que simbolizava a afluência do pós-guerra (OSGERBY, 2001). No Brasil, a noção era utilizada para remeter a personagens como Jorge Guinle e Francisco "Baby" Matarazzo Pignatari, filhos de uma burguesia cuja fortuna recém adquirida era produto da atividade industrial ou do setor de serviços. É nas colunas sociais que construíam um estilo de vida repleto de luxo, glamour e ostentação. Manuel Bandeira os definiria de forma sucinta: "Play-boy é um rapaz da moda, que sai muito, que hoje está noivo de uma pequena, amanhã de outra e que 0 Ibrahim [Sued] ${ }^{13}$ cita quase todo 0 dia na Reportagem Social ${ }^{19 "}$.

0 que singularizava o playboy era a banalização do prazer: era necessário fazer com que a rotina incessante de festas extraordinárias soasse trivial. "Refinamento", "elegância" e "discrição" eram as características intrínsecas do playboy, que traduziam sua capacidade de gozar a vida e, ao mesmo tempo, mascarar esse gozo. Isso explica a obsessão das colunas em denunciar aqueles que "se excediam" em algum evento social. Eles punham em risco a própria existência do playboy, ao deixar claro que a sublimação do gozo não tinha nada de natural, mas só poderia ser exercida graças à uma rígida hexis corporal, base do caráter distintivo do playboy.

A narrativa de vida passava pela ocultação de todo o tipo de trabalho, em especial a estafante e repetitiva labuta diária, já que ela impunha sérios limites ao gozo. 0 universo mítico em que habitavam os playboys colonizava a esfera da necessidade pelo prazer. Poucos indivíduos encarnavam tão bem 0 arquétipo desse personagem quanto o diplomata da República Dominicana Porfirio Rubirosa.

De todos os membros do International Set, esse faiscante corpo insular, cercados de champanha por todos os lados, de locomoção e moralidade fáceis, pródigo de tempo dinheiro e nervos - de todos os membros desse grupo elegante, frenético e aventureiro, nenhum se destaca tão simbolicamente como Porfirio Rubirosa (...). Conhecido por (...) leitores de colunas sociais, o diplomata da República Dominicana é piloto, esquiador, corredor de automóveis, dançarino, guitarrista, aspirante a ator e (...) prodigioso marido e amante. (...) Rubirosa é um tão perfeito protótipo global, que chega a ser difícil acreditar que ele exista mesmo. (...) Rubirosa diz: 'Não sou milionário. A ambição da maioria dos homens é juntar dinheiro. A minha é gastar.'(...) As fontes da aparente riqueza de Rubirosa são quase tão misteriosas como sua origem (...) que intrigam tanto quanto os primeiros capítulos de um romance policial..$^{14}$

13 Famoso colunista social carioca que permaneceu em atividade dos anos 50 aos $90 .{ }^{19}$ Diálogo Anteontem, Jornal do Brasil, Caderno B, 16/2/56, p.5.

14 Porfirio Rubirosa explica o segredo de seu sucesso com as mulheres, Última Hora, 23/8/57, p.3, e 24/8/57, p.3. 
Intrigando "tanto quanto os primeiros capítulos de um romance policial", ficava claro o caráter midiático e espetácular da narrativa de Rubirosa e do próprio estilo de vida dos playboys. A maneira como o playboy se constitui enquanto figura midiática está diretamente ligada à interface que estabelece com o mundo dos espetáculos, principalmente, cinematográfico. Se a riqueza material lhes parecia um atributo natural, era no campo da conquista amorosa que se dava a verdadeira disputa e atribuição de status. A popularidade de cada um era diretamente proporcional à beleza $\mathrm{e}$ fama das mulheres, principalmente das atrizes, conquistadas.

As estrelas de cinema são um produto da emergência dos grandes estúdios de Hollywood na década de 20 e de suas táticas de promoção. 0 sucesso nas telas se tornou intimamente conectado à promoção da vida privada na imprensa. Reencenada com toques de realismo, a rotina das celebridades era mais uma mercadoria oferecida para 0 consumo da audiência massiva, forjando uma performance pública da vida privada (MARSHALL, 1997). A união entre playboys e atrizes revela que ambos não podiam ser apreendidos fora de suas representações midiáticas que articulavam uma hierarquia de poder e visibilidade social. Na esteira da circulação global dos filmes norte-americanos, a fama das atrizes rodava o mundo. 0 mesmo ocorria com os playboys que já constituíam uma rede extensa e de caráter internacional.
Quem dançou, no domingo, de "par constante", no Copa, com Lana Turner, foi o senhor Jorginho Guinle. Quem trouxe Lana Turner de Punta del Este ao Rio foi o senhor Olavo Fontoura, no seu avião particular. Mas 0 senhor Andrèzinho Spittman Jordan, querendo rivalizar com Ali Khan (...) não dormiu sobre os louros de sua agitada vida de "play-boy" simpático e agradável, e foi olhar as "estrelas", ainda em terras estrangeiras, isto é, no Uruguai (... $)^{15}$.

Nesse sentido, interessa perceber como a imprensa funcionava como um agente de reconhecimento e legitimação de um estilo de vida baseado no consumo e em sua ostentação através da mídia. Por mais ficcional que parecesse, 0 universo das colunas sociais era vivido por indivíduos reais e não personagens de um romance. A sedução dos playboys se aparava nas promessas de uma sociedade afluente e capitalista em que a mobilidade social estaria ao alcance de todos. Eles funcionavam como modelos de aspiração. No entanto, o prazer e 0 lazer eram muitas vezes percebidos como símbolos de uma ordem social frágil e atomizada em que a preocupação com a coletividade parecia ceder à busca pela autogratificação.

Difundida pela imprensa, portanto, a categoria de playboy fixou no imaginário social uma atitude hedonista frente à vida que poderia ser celebrada enquanto sintoma de abundância, mas ainda ser censurada por seu caráter individualista, artificial e vazio. Nesta acepção, playboy se converte em adjetivo pejorativo; é aí que se constrói a noção de playboy transviado. 
Chocou profundamente a opinião pública a maneira cínica e debochada com a qual se apresentaram (..) os 'transviados' Cassio Murillo, adolescente de 16 anos, (..) e Ronaldo de Castro, o ‘play-boy' milionário, ambos envolvidos no crime estúpido e brutal que vitimou Aida Curi. Procedendo como dois verdadeiros cafajestes, os acusados mostraram-se de um cinismo impressionante (...). Ronaldo, o 'bon-vivant' ria e pilheriava, esquecido da profunda dor dos familiares de Aida e da revolta popular que já o tem na conta de um verdadeiro monstro insensível. ${ }^{16}$

As 20:50 horas chegou Ronaldo, trajando-se elegantemente (...) com seu 'ray-ban', paletó bege e calça escura, Ronaldo entrou sorridente. ${ }^{17}$

0 rapaz [Ronaldo] tem os cabelos muito bem penteados e do bolsinho do seu terno caríssimo sobressai um lenço, cuidadosamente dobrado. ${ }^{18}$
0 estilo de vida, marcado pela ostentação

e incessante busca pelo prazer, parecia, portanto, ser compartilhado tanto pelos colunáveis, quanto pelos desviantes. "Bon vivants", mas também "cínicos" e "cafajestes", os playboys transviados comunicam uma crítica ao hedonismo das classes abastadas e seus padrões de consumo. A representação remete à delinquência juvenil, a personagens cinematográficos como James Dean, Marlon Brando, mas também ao universo estilizado das colunas sociais, tornando os playboys transviados passíveis de serem celebrados como anti-heróis.

Figura 3: Os perfis de Cássio Murilo e Ronaldo Castro

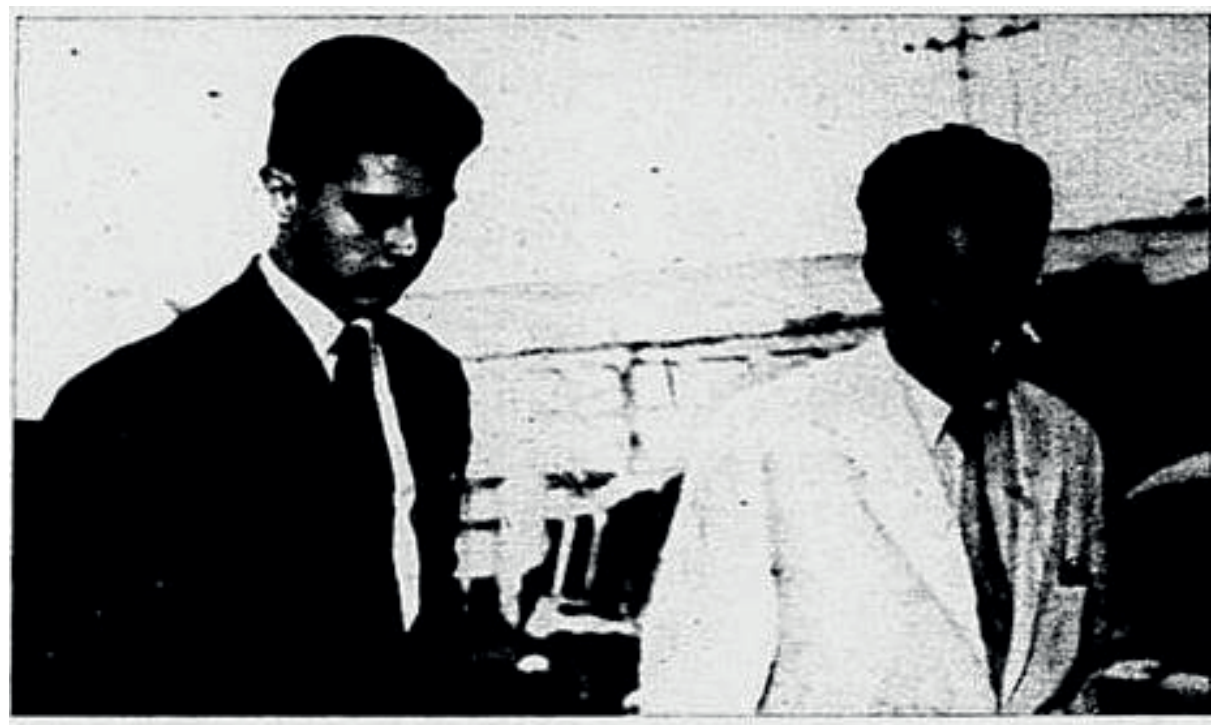

Cássio Murilo - à direita, acompanhado do advogado Celso Nascimento. Sua aparncia de bom moso näo permitiria adivinhar que

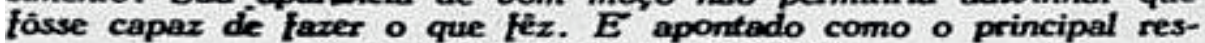
ponsável da morte de Aida 

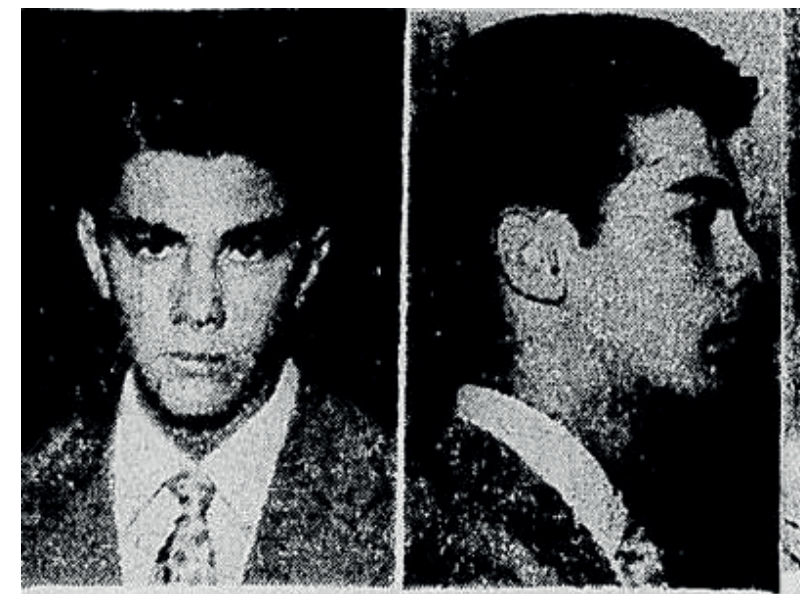

CASSIO DE FRENTE E DE PEKFIL - Nas fotos aparece o adolescentc Cássio Murilo, o principal implicado na morte de Aida Cuiri. Seus traços muito a James Dean nóo retelam de mancira alguma o que lihe vai pelo intimo.

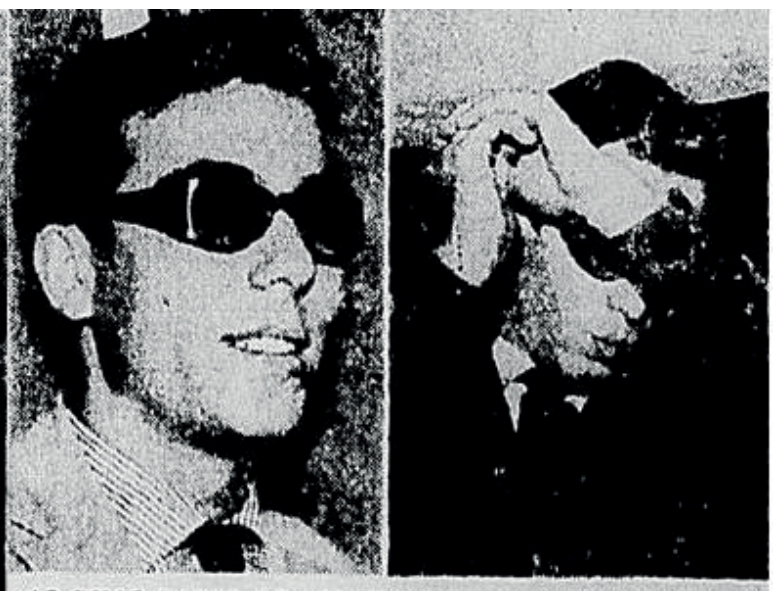

AS DUAS FACES DO "PLAY-BOY" - As totos acima definem bem a personalidale de Ronaldo de Castro a "play-bou" irresponsavel c eínico que atruiu dida Cuiri pare ala-bon." mortal. Na primeira foto, ajarece o menino bonito a curra truiu. com a maior iricza, uma vida jovem e promissora naldo entrara pela primeira vez na Delegacia Procurara csuirar-se, temeroso de ver seu rosto nos jornais acora como aparcec na scgunda foto. o jovem transviado mostra como rerdacleira face, a lace do cinismo revoltante aue arrancou do delegado scieras virerténcias. Rovaldo ri. Aida cstá morta.

Fonte: Suplemento Intergráfico Singra, Correio da Manhã, 22/8/58, p.5; Última Hora, 23/7/58, p.10.

Se era difícil se afeiçoar aos menores do SAM, o mesmo não ocorria no caso de Cássio Murilo ou Ronaldo Castro: havia algo de misterioso, desafiador e ambíguo em sua beleza e no crime cometido, justamente porque, como dito na legenda da foto acima, "a aparência de bom moço não permitiria adivinhar que fosse capaz de fazer o que fez". Uma curiosa passagem registra um misto de revolta e adoração por Cássio Murilo quando, ainda menor de idade, encontrava-se internado em um educandário de Lajes à espera da decisão final do julgamento.

Segundo notícias procedentes de Lajes, Cássio, com a permissão dos dirigentes do colégio onde se encontra, teria ido (...) assistir a um filme. Naquela casa de espetáculos, ante a estupefação geral de grande parte da audiência, inúmeras mocinhas, num impulso irreprimível de simpatia, ou, talvez, de humana solidariedade, acercaram-se do jovem (...) disputando a primazia de sentar-se ao lado do improvisado ídolo. Este fato, aos chefes de família da cidade, teria motivado o protesto no sentido de alijá-lo do colégio onde se encontra $(. . .)^{19}$.

Na mesma linha, é descrito o dia em que o jovem depôs na polícia: "passados poucos minutos da chegada de Cássio, a rua (...), na qual está situado o $12^{\circ}$ distrito, encheu-se de 'lambrettas' (sic) e garotas em 'blue jeans' que procuravam avistar a rapazola que volta e meia chegava à janela, não mais trazendo em seus lábios 0 sorriso constante que o caracteriza" ${ }^{20}$. Atuando como uma celebridade, o jovem, rico e atraente, representava o simétrico oposto de Rubirosa e ainda era dotado de um mórbido fascínio, 
conferido por sua capacidade de cometer uma atrocidade por motivos enigmáticos. Tal como 0 diplomata, "chega a ser difícil acreditar que ele exista mesmo"27.

Isso mostra como as narrativas dos meios de comunicação alimentam-se umas das outras, evidenciando o seu caráter intertextual. Fica claro, portanto, como as narrativas, mesmo aquelas claramente ficcionais, acabam por invadir e fornecer as bases interpretativas para o real. Assim, por mais construídas que sejam as representações midiáticas, elas não são menos válidas como índices de interpretação da sociedade.

\section{Considerações finais}

Segundo Graham Murdock (1997), ao explorarem o sensacional, o grotesco e o violento, a mídia joga com a falência dos ideais de ordem, respeito e racionalidade que estão no coração do projeto moderno, sendo, assim, culpadas pelos males sociais. A recorrência do tema deixa clara a dificuldade que temos em encarar os custos morais e espirituais das mudanças nas sociedades capitalistas modernas onde tudo que é sólido desmancha no ar, tal como postulava Marx. Tendese a reduzir a questão a um único agente externo que teria a possibilidade de manipular a sociedade a partir de cima. Vimos, no entanto, que os meios de comunicação, implicados na construção das noções que possuímos sobre a ordem social, são 0 sintoma e 0 agente de uma ordem social em permanente modificação.
0 debate sobre a delinquência juvenil, portanto, torna-se o ponto de encontro de uma série de anseios a respeito das novas modificações pelas quais atravessava a paisagem urbana, cada vez mais cosmopolita e heterogênea socialmente. 0 jovem, assim, é ao mesmo tempo o retrato de um presente que se modificava e das promessas de um futuro incerto. Esse personagem serve para expressar as ambiguidades de uma sociedade que se modernizava economicamente, mas que parecia sofrer de uma decadência moral.

Isso mostra como a juventude funciona como arena de disputa simbólica. 0s playboys transviados, surgidos como figura inédita no imaginário social, representavam um desafio. Como classificar um indivíduo que combinava uma imagem de prosperidade tão típica com um comportamento tão reprovável socialmente? Lido enquanto produto de um ambiente urbano miscigenado, uma classe média ascende e uma indústria de bens culturais especificamente juvenis, esse novo jovem parecia cristalizar o lado, ao mesmo tempo, mais brilhante e mais sombrio de uma nova ordem social. Ele condensava a promessa da inserção do Brasil em uma nova ordem social, orientada não só pelo aumento da produção, mas sobretudo pela democratização do luxo e pela generalização do consumo.

Celebrado nas colunas sociais e criticado nas páginas policiais, esse novo personagem representava o retrato ambivalente de uma sociedade extremamente segregada e incerta 
quanto ao processo de rápida mutação que atravessava. Através do jovem, portanto, as promessas otimistas sobre 0 futuro são questionadas e problematizadas, revelando um retrato mais complexo dos supostos "anos dourados". Com isso, mostramos ser o discurso midiático uma arena fundamental para a construção e, ao mesmo tempo, crítica da ordem social, um espaço, portanto, de lutas.

\section{Referências}

ACLAND, Charles R. Youth, Murder, Spectacle: The Cultural Politics Of "Youth In Crisis". Nova York: Westview Press, 1994.

BECKER, Howard. Falando da sociedade: ensaios sobre as diferentes maneiras de representar o social. Rio de Janeiro: Jorge Zahar Editor, 2009.

BENEVIDES, Maria Victoria. 0 Governo Kubischek

- 1956-1961: o desenvolvimento econômico e estabilidade política. Rio de Janeiro: Paz e Terra, 1979

BOURDIEU, Pierre. A economia das trocas linguísticas: o que falar quer dizer. São Paulo: EDUSP, 1996

\section{. A Distinção: Crítica Social do}

Julgamento. São Paulo: Zouk, 2007.

DURKHEIM, Émile. Formas elementares da vida

religiosa: 0 sistema totêmico na Austrália. São Paulo:

Paulinas, 1989

FREIRE FILHO, João. Formas e normas da adolescência e da juventude na mídia. In: FREIRE FILHO, João; VAZ, Paulo. (Org.). Construções do tempo e do outro: representações e discursos midiáticos sobre a alteridade. Rio de Janeiro: Mauad X, 2006, p. 37-64.

GILBERT, James. A Cycle of outrage America's

Reaction to the Juvenile Delinquent in the $1950 \mathrm{~s}$.
Oxford: Oxford University Press: 1988.

HALL, Stuart. Representation. Cultural representation and signifying practices. Londres: Sage, 1997.

The Whites of Their Eyes: Racist Ideologies and the Media, in BRIDGES, George; BRUNT, Rosalind (orgs), Silver Linings: Some Strategies for the Eighties. Londres: Lawrence and Wishart, 1981. p.28-52.

. A redescoberta da ideologia: o retorno do recalcado nos estudos midiáticos. In: RIBEIR0, Ana Paula Goulart; SACRAMENTO, Igor (orgs.). Mikhail Bakhtin: linguagem, cultura e mídia. São Carlos: Pedro \& João Editores, p.279-329.

HALL, Stuart; JEFFERSON, Tony (eds.). Resistance through rituals: youth subcultures in postwar Britain. London: Hutchinson, 1976.

LENHARO, Alcir. Cantores do Rádio: A trajetória de Nora Ney e Jorge Goulart no meio artístico do seu tempo. Barão Geraldo: Editora da Unicamp, 1995.

MARSHALL, D. P. Celebrity and power: fame in contemporary culture. Minneapolis :University of Minnesota Press, 1995.

MOSCOVICI, Serge, 1978. A Representação Social da Psicanálise. Rio de Janeiro: Zahar.

MURD0CK, Graham. Reservoirs of dogma: an archaeology of popular In: BAKER, Martin; PETLEY, Julian. Ill Effects: The Media/Violence debate. Londres: Routledge, 1997, p.150-169.

MELO, João Manuel Cardoso de; e NOVAIS, Fernando. Capitalismo Tardio e Sociabilidade Moderna. In: NOVAIS, Fernando A. História da Vida Privada no Brasil: Contrastes da intimidade contemporânea. São Paulo: Companhia das Letras, 1998. ORTIZ, Renato. A moderna tradição brasileira. São Paulo: Ática, 1988

OSGERBY, Bill. Playboys in Paradise: Masculinity, Youth and Leisure-Style in Modern America. Oxford: Berg, 2001. 
PALLADINO, Grace. Teenagers: An american history. Nova York: Basic Books, 1997.

PASSERINI, Luisa. A juventude, metáfora da mudança social. Dois debates sobre os jovens: a Itália fascista e os Estados Unidos da década de 50" In: LEVI, Giovanni; SCHMITT, Jean Claude (orgs.) História dos Jovens. A época contemporânea Vol. 2. São Paulo: Cia Editora das Letras, 1996.

SANTOS, Lidia Noemia. A invenção da juventude transviada no Brasil (50-70). Tese de Doutorado em Sociologia, PUC-SP, São Paulo, 2013.

SERCOMBE, Howard. Naming Youth: The construction of the youth category. 1996. Tese de doutorado em Filosofia, Murdock University, Western Australia, 1996. Disponível em: http://researchrepository.murdoch. edu. au/298/. Acesso em 22/2/2015.

VELHO, Gilberto. A utopia urbana: um estudo de antropologia social. Rio de Janeiro: Zahar, 1972. 


\section{The Aída Cury case:}

\section{playboys and wayward youth}

\section{as representations of the}

\section{youth in modern times}

\section{Abstract}

Raped and thrown from a building by two juveniles, Ronaldo Castro and Cassio Murilo, the young Aida Cury, was found on the morning of July 14, 1958 laying on the sidewalk of Copacabana. The national awareness of this crime made middle class juvenile delinquency a central topic of the great Brazilian press of the late 50's. Taken as a symptom and product of a new social order, so-called "playboys" existing as a product of media representations - help to uncover the ambivalences of a historical period commonly associated with generalized optimism. The purpose of this article, therefore, is to understand how these playboys summoned the consequences of national modernization, a project based on the urban landscape, where cosmopolitanism, progress and social diversity could mean promiscuity, vice and moral corruption.

\section{Keywords}

Juvenile delinquency. Social representation. 50's.

\section{El caso Aída Cury: playboys y} transviados como representaciones

\section{de la juventud en tiempos} de modernización

\section{Resumen}

Violada y tirada de un edificio por los jóvenes Ronaldo Castro y Cassio Murilo, la joven Aida Cury amaneció el 14 de julio de 1958 estirada en la acera de Copacabana. De repercusión nacional, ese crimen hizo que la delincuencia juvenil de clase media se convirtiera en un tema central de la gran prensa brasileña de fines de los años 50. Tomados como síntoma y producto de un nuevo orden social, los llamados "playboys transviados" - existiendo por y a través de sus representaciones mediáticas, ayudan a descortinar las ambivalencias de un período histórico comúnmente asociado a un optimismo generalizado.

El objetivo de este artículo, por lo tanto, es percibir cómo estos personajes dramatizaban las consecuencias del proyecto de modernización nacional basado en la metrópoli, espacio en que progreso, cosmopolitismo y diversidad social podrían significar promiscuidad, vicio y corrupción moral.

\section{Palabras clave}

Delincuencia juvenil. Representación social. Años 50. 


\section{Expediente}

A revista E-Compós é a publicação científica em formato eletrônico da Associação Nacional dos Programas de Pós-Graduação em Comunicação (Compós). Lançada em 2004, tem como principal finalidade difundir a produção acadêmica de pesquisadores da área de Comunicação, inseridos em instituições do Brasil e do exterior.

\section{E-COMPÓS I www.e-compos.org.br I E-ISSN 1808-2599}

Revista da Associação Nacional dos Programas de Pós-Graduação em Comunicação. Brasília, v.20, n.2, maio/ago. 2017. A identificação das edições, a partir de 2008, passa a ser volume anual com três números. Indexada por Latindex I www.latindex.unam.mx

\section{CONSELHO EDITORIAL}

Alda Cristina Silva da Costa, Universidade Federal do Pará, Brasil Alfredo Luiz Paes de Oliveira Suppia, Universidade Estadual de Campinas, Brasil Álvaro Larangeira, Universidade Tuiuti do Paraná, Brasil Ana Carolina D. Escosteguy, Pontifícia Universidade Católica do Rio Grande do Sul, Brasil Ana Regina Barros Rego Leal, Universidade Federal do Piauí, Brasil Ana Carolina Rocha Pessôa Temer, Universidade Federal de Goiás, Brasil Andrea França, Pontifícia Universidade Católica do Rio de Janeiro, Brasil André Luiz Martins Lemos, Universidade Federal da Bahia, Brasil Angela Cristina Salgueiro Marques, Faculdade Cásper Líbero, Brasil Ângela Freire Prysthon, Universidade Federal de Pernambuco, Brasil Antonio Carlos Hohlfeldt, Pontifícia Universidade Católica do Rio Grande do Sul, Brasil Arthur Ituassu, Pontifícia Universidade Católica do Rio de Janeiro, Brasil Bruno Campanella, Universidade Federal Fluminense, Brasil Cláudio Novaes Pinto Coelho, Faculdade Cásper Líbero, Brasil Carlos Eduardo Franciscato, Universidade Federal de Sergipe, Brasil Denise Tavares da Silva, Universidade Federal Fluminense, Brasil Eduardo Vicente, Universidade de São Paulo, Brasil Eliza Bachega Casadei, Escola Superior de Propaganda e Marketing - SP, Brasil Elizabeth Nicolau Saad Corrêa, Universidade de São Paulo, Brasil Erick Felinto de Oliveira, Universidade do Estado do Rio de Janeiro, Brasil Erly Vieira Júnior, Universidade Federal do Espírito Santo, Brasil Francisco de Assis, FIAM-FAAM Centro Universitário, Brasil Francisco Elinaldo Teixeira, Universidade Estadual de Campinas, Brasil Frederico de Mello Brandão Tavares, Universidade Federal de Ouro Preto, Brasil Gabriela Reinaldo, Universidade Federal do Ceará, Brasil

Gilson Vieira Monteiro, Universidade Federal do Amazonas, Brasil Gustavo Daudt Fischer, Universidade do Vale do Rio dos Sinos, Brasi Itania Maria Mota Gomes, Universidade Federal da Bahia, Brasil Jiani Adriana Bonin, Universidade do Vale do Rio dos Sinos, Brasil José Afonso da Silva Junior, Universidade Federal de Pernambuco, Brasil José Luiz Aidar Prado, Pontifícia Universidade Católica de São Paulo, Brasi
Juçara Gorski Brittes, Universidade Federal de Ouro Preto, Brasil Juliana Freire Gutmann, Universidade Federal da Bahia, Brasil Laura Loguercio Cánepa, Universidade Anhembi Morumbi, Brasil Letícia Cantarela Matheus, Universidade do Estado do Rio de Janeiro, Brasil Liziane Soares Guazina, Universidade de Brasília, Brasil Luíza Mônica Assis da Silva, Universidade Católica de Brasília, Brasil Maria Ataide Malcher, Universidade Federal do Pará, Brasil Maria Elisabete Antonioli, Escola Superior de Propaganda e Marketing - SP, Brasil Maria das Graças Pinto Coelho, Universidade Federal do Rio Grande do Norte, Brasil Marcel Vieira Barreto Silva, Universidade Federal da Paraiba, Brasil Marcia Tondato, Escola Superior de Propaganda e Marketing, Brasil Marli Santos, Universidade Metodista de São Paulo, Brasil Márcio Souza Gonçalves, Universidade do Estado do Rio de Janeiro, Brasil Mauricio Mario Monteiro, Universidade Anhembi Morumbi, Brasil Mauricio Ribeiro da Silva, Universidade Paulista, Brasil Mauro de Souza Ventura, Universidade Estadual Paulista, Brasil Mayka Castellano, Universidade Federal Fluminense, Brasi Micael Maiolino Herschmann, Universidade Federal do Rio de Janeiro, Brasil Mozahir Salomão Bruck, Pontifícia Universidade Católica de Minas Gerais, Brasil Nísia Martins Rosario, Universidade Federal do Rio Grande do Sul, Brasil Potiguara Mendes Silveira Jr, Universidade Federal de Juiz de Fora, Brasil Rafael Grohmann, FIAM-FAAM - Centro Universitário, Brasil Raquel Ritter Longhi, Universidade Federal de Santa Catarina, Brasil Regiane Regina Ribeiro, Universidade Federal do Paraná, Brasil Roberto Elísio dos Santos, Universidade Municipal de São Caetano do Sul, Brasil Rodolfo Rorato Londero, Universidade Estadual de Londrina, Brasil Sérgio Luiz Gadini, Universidade Estadual de Ponta Grossa, Brasil Simone Maria Andrade Pereira de Sá, Universidade Federal Fluminense, Brasil Simone Maria Rocha, Universidade Federal de Minas Gerais, Brasil Suzana Reck Miranda, Universidade Federal de São Carlos, Brasil Tarcyanie Cajueiro Santos, Universidade de Sorocaba, Brasil Tatiana Oliveira Siciliano, Pontifícia Universidade Católica do Rio de Janeiro, Brasil Veneza Mayora Ronsini, Universidade Federal de Santa Maria, Brasil

\section{CONSELHO CIENTÍFICO}

Cristiane Freitas Gutfreind, Pontifícia Universidade Católica do Rio Grande do Sul, Brasil | Eduardo Antônio de Jesus, Universidade Federal de Minhas Gerais, Brasil | Eduardo Morettin, Universidade de São Paulo, Brasil I Irene de Araújo Machado, Universidade de São Paulo, Brasil I Miriam de Souza Rossini, Universidade Federal do Rio Grande do Sul, Brasil

\section{COMISSÃO EDITORIAL}

Eduardo Antonio de Jesus, Universidade Federal de Minas Gerais, Brasil I Igor Pinto Sacramento, Universidade Federal do Rio de Janeiro, Brasil I Kelly Cristina de Souza Prudencio, Universidade Federal do Paraná, Brasil I Osmar Gonçalves dos Reis Filho, Universidade Federal do Ceará, Brasil

\section{CONSULTORES AD HOC}

Cesar Augusto Baio Santos, Universidade Federal do Ceará, Brasil I Lilian França Universidade Federal de Sergipe, Brasil I Maria Aparecida Baccega, Escola Superior de Propaganda e Marketing, Brasil I Márcia Benetti, Universidade Federal do Rio Grande do Sul, Brasil I Miguel Serpa Pereira, Pontifícia Universidade Católica do Rio de Janeiro, Brasil | Renato Essenfelder, Escola Superior de Propaganda e Marketing, Brasil

\section{EQUIPE TÉCNICA}

ASSISTENTE EDITORIAL Márcio Zanetti Negrini | REVISÃO DE TEXTOS Melina Santos | EDITORAÇÃO ELETRÔNICA Roka Estúdio I IMAGEM DE CAPA Silas de Paula

COMPÓS I www.compos.org.br

Associação Nacional dos Programas de Pós-Graduação em Comunicação

Presidente

Marco Roxo

Programa de Pós-Graduação em Comunicação - UFF marcos-roxo@uol.com.br

Vice-Presidente Isaltina Gomes Programa de Pós-Graduação em Comunicação - UFPE isaltina@gmail.com

Secretária-Geral

Gisela Castro

Programa de Pós-Graduação em Comunicação e Práticas de Consumo - ESPM castro.gisela@gmail.com

CONTATO I revistaecompos@gmail.com 